\title{
A TRANSACTION COSTS APPROACH \\ TO FINANCIAL ASSETS RATES OF RETURN
}

\author{
Rodolfo Apreda \\ Universidad del Cema \\ ra@cema.edu.ar
}

\begin{abstract}
This paper expands on the extent of the gap between how academic teaching view market transactions and how the market professionals actually work, offering a sensible way of closing as much as possible such a gap. Firstly, transaction costs will be analysed from both the demand and supply sides of securities trading, featuring the essential role intermediaries usually performs. This analysis will lead us to a careful survey of the structure of the transaction costs function, bearing in mind that different users meet different cost items. Next, the concept and usage of differential rates will be set forth, distinguishing the stock from the flow differential rates, in the framework of an innovative approach inclusive of information sets. Afterwards, it is showed that transaction costs can be measured by rates which are differential ones by themselves. This addresses to an explicit transaction costs function, within a multiplicative model of differential rates. Besides, three simple lemmas are proved to give foundations to some statements included in the paper. Finally, some numerical examples are provided to illustrate algorithms and concepts.
\end{abstract}

JEL: D23, G12, M41

Key words: transaction costs; rates of return; differential rates; microstructure 


\section{1.- INTRODUCTION}

In order that any buying, short-selling, holding, or selling transaction of a financial asset might be rounded off, economic agents incur a wide structure of costs associated with the whole transaction along the horizon [ $\mathrm{t} ; \mathrm{T}$ ] . This paper expands on the extent of the gap between how academic teaching view market transactions and how the market professionals actually work, offering a sensible way of closing as much as possible such a gap.

Prior to the 1970's, it was customary to neglect transaction costs, not only in Finance but in Economics. However, this issue has become topical since then, when a reappraisal of Coase's ideas took place and, furthermore, the Transaction Costs Approach was strongly developed by Demsetz (1968) and Williamson (1996), among others.

From the Finance side, on the other hand, seminal work laid the foundations of three new and incipient theories, dealing respectively with market microstructure, incomplete contracts and agency problems. Besides, a distinctive stress on the intermediary's role in the financial markets pervades all these approaches. (Spulberg provides a good introduction to intermediation, 1998).

It seems timely to remember here two remarks the distinguished economist Arthur Okun wrote in his well known book "Prices and Quantities" (Okun, 1981):

- "So even though money provides no explicit income, it is held because it saves transaction costs"

- " $\quad$ Suppose that the interest rate on a Treasury Bill is 8 per cent a year, and that is costs one per cent over face value to acquire and to sell it. Then it would take three months to generate enough interest income to cover the in-and-out transaction costs. "

\section{Remark on e-commerce:}

Oncoming events from the Internet e-commerce have made some people think that there will be a wide desintermediation wave and hence transaction costs should be lower. On the opposite side, some other people think there will be hypermediation with a huge array of new intermediaries and transaction costs. A cute insight on the prospective debate has been presented in Harvard Business Review, January-February 2000. In particular, it is worthy of reading the article by Nicholas Carr.

What we want to do in this paper can be broken down into the following stages:

Firstly, transaction costs are analysed from both the demand and supply sides of securities trading, featuring the essential role intermediaries usually performs. This analysis will lead us to a careful survey of the structure of the transaction costs function, bearing in mind that different users meet different cost items.

Next, the concept and usage of differential rates are set forth, distinguishing the stock from the flow differential rates, in the framework of an innovative approach inclusive of information sets. 
Afterwards, it is showed that transaction costs can be measured by rates which are differential ones by themselves. This addresses to an explicit transaction costs function, within a multiplicative model of differential rates.

Besides, three simple lemmas are proved to give foundations to some statements included in the paper. On the other hand, each lemma conveys a functional algorithm to cope with net ret of return and global differential rates that stand for transaction costs. Finally, some numerical examples are provided to illustrate algorithms and concepts.

\section{2.- TRANSACTION COSTS}

What are the main costs we find when buying, short-selling, holding, issuing, repurchasing, or selling, a financial asset? To give a sensible answer to this question it will prove useful to briefly track down the demand and supply sides of financial assets, and the widespread role of intermediaries. After this development, the main types of transaction costs will be highlighted and the transaction costs function will be presented.

However, we must advance a caveat before proceeding with the contents of this section.

- Different users meet different costs.

- When breaking down the main components in the transaction costs function, it should not come as a surprise that some of those items overlap. For instance, information costs or microstructure costs could be partially accounted in the dealer's spread, which is a cost of intermediation.

- At figuring out the main components for a particular transaction costs function, we have to bear in mind the former remark by netting up the rates so as to avoid double accounting. By the way, this is usual when computing a corporate rate bond adjusted by risk, taking first the free-risk rate, then the country risk rate, and later the corporate credit risk net of country risk.

a) Demand Side of Financial Assets

The demand side is the place where the economic agent buys, short-sells, holds or sells assets, motivated by a wide variety of purposes: hoarding, hedging, investment, arbitrage, speculation, or liquidity.

Who are these economic agents? Individuals, households, corporations, institutional investors, a wide array of financial intermediaries (from investment banks to market-makers), and even governments.

\section{b) Supply Side of Financial Assets}

The supply side is the place where the economic agent produces his own financial instruments to be offered in the market, or provides with them from his own inventory. This can be accomplished in three basic ways: 
- Primary Supply Market:

Corporations, Governments, Financial Intermediaries, even small and medium size companies, all of them produce primary securities to be offered by means of public or private placements.

- Secondary Supply Market:

Economic agents trade securities in the secondary markets, either those which were publicly placed or privately placed. In some countries, institutional investors have an specific market to exchange private placements between them (In the United States this trading is regulated by Rule A-144 on which a good analysis is found in Carey et al (1993).

- Reverse Secondary Market:

It is the place where issuers call back their primaries securities, or repurchase them in the market. This amounts to a sort of reverse supply.

\section{c) The Role of Financial Intermediaries}

Financial intermediaries supply with and demand for financial assets issued by third parties and, in some cases, by themselves. In doing so, they diminish transaction costs, improve the market efficiency, help to price discovery. It is for dealers, market makers and specialists to provide with liquidity and immediacy (Demsetz, 1968).

On the other hand, Benston and Clifford Smith (1976) pointed out that the whole industry of financial services may be explained by transaction costs. In fact, if financial markets were competitive in the classical sense, there would be neither intermediaries nor transaction costs.

For a detailed account of financial intermediaries and the problems they are able to solve in the financial system, Blake (1999) gives an updated and accurate description. Spulber (1996) seems a provocative paper on intermediation, as well.

\subsection{1.- THE TRANSACTION COSTS STRUCTURE}

A transaction cost structure comprises a variety of cost items, and we believe that the following format accounts for the most relevant of them eventually, either within a single market $\mathbf{m}_{1}$, or between markets $\mathbf{m}_{1}$ and $\mathbf{m}_{2}$ involved in the whole transaction. In the former case, we have $\mathbf{m}_{1}$ $=\mathrm{m}_{2}$, and the notation becomes easier to follow than in the latter. By the same token, if the transaction only last a moment (for instance, selling an asset outright), then we are going to make $\mathbf{t}=\mathbf{T}$. We will take profit of vectorial notation, which means that we plug whatever variable could be relevant to certain context of analysis, and take out whatever variable is felt as not suitable in another context. 
Afterwards, a list of those costs we think as distinctive will follow. In each case, remarks will be found to focus on whether each item comes from the demand or supply sides. We have to bear in mind that the list is not exhaustive but functional, and also that different users face different costs.

\section{INTERMEDIATION COSTS $\quad$ INT $\left(\mathrm{t} ; \mathrm{T} ; \mathrm{m}_{1} ; \mathrm{m}_{2}\right)$}

Intermediation costs are put together into four groups: execution, portfolio management, flotation and logistics costs.

\section{- Execution Costs}

a) Brokerage fees that brokers charge at performing buying or selling orders on behalf of their customers, and also as a reward for reducing uncertainty associated with making satisfactory matching between sellers and buyers.

b) The dealers' bid-ask spread, which attempts to cover their costs and reward them from trading. Microstructure theory stresses that dealers and market makers set the bid-ask spread mainly to cover four types of trading costs: risk of holding inventories, costs of processing orders, the adverse selection problems (costs of trading with more informed investors) and search costs.

Although adverse selection costs and search costs are items whose proper place seems to be within the information costs, it is worthy of remark here that search costs amount to one third of the bid ask spread in some markets, as Flood et al (1998) have proved.

c) It is for the demand side that dealers transfer the "supply of immediacy" costs, because they provide with immediacy to the demand side of financial assets. (Demsetz, 1968). By the same token, dealers transfer the "supply of liquidity" costs to securities sellers.

d) Price impact of the trade: investors and dealers push prices up when they buy, and push prices down when they sell. That is to say, after trading, they lose mark-ups or mark-downs that come as a consequence. The more illiquid the market, the bigger the transaction costs.

\section{- Portfolio Management Costs}

a) Besides execution costs, we have to considere that the more frequent the assets turnover is carried on, the higher transaction costs become.

b) Portfolio Management Fees: here we meet a wide range of costs, which turn out to be frequent and expensive whenever the economic agent engages himself in a principal-agent relationship with investment funds like mutual funds, private equity or venture capital funds, pension funds, fiduciary funds.

c) Costs of waiting: investors would eventually buy at a much higher price that if they had bought without delay, or the price rises so much that the asset lacks any profitable prospect. The same for sellers. We touch on this later when dealing with information costs. 


\section{- Flotation Costs}

a) Primary issuers of securities cope with the cost of the placement in the market, either in private or in public placements.

b) When the placement is public, intermediaries and the issuer engage their efforts in underwriting processes which involve heavy costs to issuers.

c) When the placement is private, transactions costs can be heavy, not only with intermediaries fees but contracting, covenants restrictions and asymmetric information issues, that is to say, with information costs.

\section{- Logistics Costs}

a) Transportation Costs: of securities or collaterals or currencies, carried on by banks, dealers, corporations, within the domestic market or across foreign marktes.

b) Storage Costs: custodial care fees of securities, charged by banks or exchanges, and collateral maintenance costs as well.

c) Insurance Costs: involved in safety measures taken by regulators on deposits, or insurance companies when taking private placements of corporate bonds.

d) Trustee Fees and Expenses: this is an increasing item of cost whenever we can find trust funds and securitization processes.

\section{$\underline{\text { TAXES }}$}

$\operatorname{TAX}\left(t ; T ; m_{1} ; m_{2}\right)$

Taxes diminish incoming cash flows, and increase outgoing cash flows whenever financial assets are traded, like all other transaction costs. That's why is necessary to include them in the transaction costs structure. (Taxes as transaction costs are treated in Jeffrey, 1998-a, 1998-b)

a) The two most important taxes to influence a security holding period are the Income Tax and the Capital Gains Tax. In this way, interests, dividends and holding returns are taxed. Besides, companies issuing bonds are taxed on his interests paid during the yearly period.

b) Value Added Tax is collected on many cash flow streams, not only with some bonds, but in bank loans, and some types of financing coming from abroad. Customs taxes could be significative in some financing services among which we can find transaction costs (mainly information costs, and transfer costs).

c) Stamp taxes are widespread in debt issuances and underwritings, on physical collaterals for bonds and mortgages, and certain transfers of financials.

d) Public placements are exempted from some taxes, but private placements are not. Some institutional investors qualifies to be exempted from certain taxes, as well. 


\section{MARKET MICROSTRUCTURE COSTS $\quad \operatorname{MICR}\left(\mathrm{t} ; \mathrm{T} ; \mathrm{m}_{1} ; \mathrm{m}_{2}\right)$}

Among the most pervasive and exacting sources of costs brought about by the so called Market Microstructure, we can pick up the following:

a) Regulations on volume, frequency of trading, size orders, the types of exchanges allowed, entrance and exit restrictions.

b) Institutional Investors meet restrictions to trade with certain financial assets, mainly by facing ceilings or floors to the percentage of those assets that could be held in portfolios.

c) Limits to short selling transactions, with outright banishment in some capital markets.

d) Financial assets are not divisible as standard text-books set forth, for the ease of models and presentations.

e) Traders usually quote financial assets by fractions, instead of using a continuous convention as in other commodities markets.

f) Loan and marginal accounts restrictions: any time that loans and marginal accounts are regulated with boundaries or caveats, as it is usual in most capital markets, we cannot build up the portfolio we wish. In most cases, transaction costs increase, too.

g) Holding Costs: at least, part of margin deposits may not earn interest. Also, part or the whole of a short selling proceedings, are not disposable. Both situations bring about holding costs.

h) Benston y Clifford Smith (1976) highlighted four types of costs that financial intermediaries usually meet: licence costs, price setting regulations, credit allocation restrictions, and supervision costs. We add those costs that institutional investors confront as supervision costs through government or exchange agencies.

\section{INFORMATION COSTS $\quad$ INF $\left(\mathrm{t} ; \mathrm{T} ; \mathrm{m}_{1} ; \mathrm{m}_{2}\right)$}

Information costs are those incurred by the economic agent when he searches or pays for information, when contracting with intermediaries, when he faces agency costs which come up from the transactions he engages in. There are four types of information costs that deserve a closer look:

\section{- Williamson's Transaction Costs}

a) In fact, within the information costs we should include those costs Williamson (1996) labeled "transaction costs", with a meaning much narrower than they are used in Finance. In his own words: " ex ante costs of drafting, negotiating and safeguarding an agreement and, more specially, the ex post costs of maladptation and adjustment because of gaps, errors, ommissions or disturbances" 
b) These type of costs, so cutely remarked by Williamson, are distinctively expensive in complex transactions like swaps, or private placements with institutional investors

\section{- Treynor's Invisible Costs of Trading}

These costs arise from the inefficiencies of capital markets and cannot be explained by direct transaction costs, in the Williamson's meaning. Treynor (1994) called them invisible " because the trader won't know what information made his bargain possible until it bags him. " They amount to the opportunities costs of waiting.

If the investor waits to buy an undervalued asset, he will face two likely outcomes:

a) He buys at a higher price reducing the expected profit.

b) The price rises so much that trade is not more advisable.

A similar remark could be stated if the investor waits to sell any overvalued asset.

\section{- Adverse Selection Problem}

This problem, and their side costs, stems from asymmetric information. When engaged in transactions, dealers and investors are parties who trade with different information. This can be to the advantage of one party and to the damage of the counterparty, because the former can know some features that remain hidden to the latter who in this way not only underperforms but foot the bill. Well known examples in practice are provided by banks when bad loans cannot be distinguished from good ones, and from dealers troubles when they can tell apart well valued securities from poorly valued ones.

\section{- Search Costs}

As most of the world's capital markets are not still consolidated, dealers have to search for the best counterparties and this means transaction costs. For every transaction we can measure both the actual price and the best price in the market at that time. The gap between actual price and best price comes as a measure of such costs. Flood et al (1998) showed that this sort of costs adds up to a third of the bid-ask spread.

\section{FINANCIAL COSTS}

$\operatorname{FIN}\left(t ; T ; m_{1} ; m_{2}\right)$

Short-selling and buying financial assets, when backed by marginal accounts or loans, bring about financial costs to the demand for securities. We also have to include here the risk management costs, which could be quite weighty in the over the counter market and to the Corporate Treasury.

\section{- Marginal accounts}

There are two main types of accounts that investors can keep with their brokers or dealers, both of which bring out transaction costs: 
a) Cash Account, where deposits are made under the guise of cash or revenues from securities sold, and their counterparts, withdrawals of cash or from security purchases.

b) Margin Account, that is like a cash account but with an overdraft limit. It allows to buy securities with credit supplied by the broker, who keeps them as collateral and charges interest on their loans and administrative fees for managing them on behalf of their customers.

Furthermore, when the investor believes that certain security price is going to fall, he resorts to short-selling, by which the dealer lends him the security and keep the proceedings of its sale as collateral. In this case, the dealer also requires initial and maintenance margin payments on the investor's account.

\section{- Loans}

Another item in this category comes under the loans intermediaries and investors must face in order to round off their transactions. Apart from an outright short term bank loan, two basic instruments made way in the financial market:

a) Repurchase Agreements, which are arrangements where part A sells a security to part B at valuation date " $t$ " and contracts at that date the repurchase of the security to take place later at date " $\mathbf{T}$ ", at an agreed price and delivery conditions. In this way A gets a loan in cash collateralized by the security. Many dealers engage themselves in Repo, performing as A or $B$, when they are in need of liquidity or securities.

b) Reverse Repurchase Agreemens, is the repurchase agreement from the side of part $B$. It is called a Reverse or resale.

A brief and state-of-the-art development on margin account and repos can be found in Blake (1999), with focus on London market.

\section{- Risk Management}

Financial risks are mainly found in the unpredictable fluctuations of interest rates, commodities prices and foreign exchange rates. To cope with these risks, an impressive wave of innovations has been stirring the markets since the 1970's. Therefore, simple and complex derivatives are traded (options, futures, forwards, swaps, and a wide variety of "combos"). Market intermediaries and end-users open risky positions whenever they trade, and here is when derivatives come in handy to hedge, arbitrage, hoard, speculate, short-sell. The impressive amount of nominal and notional principals involved are met by relevant transaction costs. The dealer, for instance, faces margin accounts and collateral restrictions. End-users have to cope with intermediaries fees. Mainly in the over the counter market, swaps provide a good example of the pervading impact of transaction costs, which are not only the trading costs, as most presentations seems to make us believe. On this issue, Marshall and Kapner (1993) provide a good account of the "all-in" cost approach to swaps. 


\subsection{2.- THE TRANSACTION COSTS FUNCTION}

Although the five categories displayed in the former section are neither exhaustive nor the only ones to work with, we believe that they allow for a sensible assessment of a total transaction costs function we are going to denote $\mathrm{TC}\left(\mathrm{t} ; \mathrm{T} ; \mathrm{m}_{1} ; \mathrm{m}_{2}\right)$, which is a construct that comes by the side of every single transaction and may be framed by a functional relationship:

[01]

$$
E\left[T C\left(t ; T ; m_{1} ; m_{2}\right)\right]=f(\text { INT, TAX, MICR , FIN , INF })
$$

In next section, we give an explicit version of this functional relationship, within a multiplicative model of differential rates.

We remark at this place that each component has its own functional structure which does not come up as linear, necessarily. In fact, non-linearity is customary and useful in standard research, which take advantage of piece-wise linear functions, or still better, the so called simple or step funtions, so as to approximate more complex relationships. [For instance, Levy-Livingston (1995) on portfolio management, Day (1997) in nonlinear dynamics applied to economics, Herschell Grossman (1974) on imperfect markets]

\section{3.- DIFFERENTIAL RATES}

Let us suppose that in forecasting a rate of interest for a financial asset at valuation date " $\mathrm{t}$ ", in terms of the available set of information $\boldsymbol{\Omega}_{\mathrm{t}}$, to be held along the horizon [ $\mathrm{t} ; \mathrm{T}$ ], we get:

$$
E\left[r\left(t, T, \Omega_{t}\right)\right]
$$

Ex post, however, the actual rate of interest at valuation date " $\mathbf{T}$ " comes up as

$$
r(t, T)
$$

If we wished to measure the gap, $\mathbf{g}(\mathbf{t}, \mathbf{T})$, arising between both rates

$$
g\left(t, \Omega_{t} \rightarrow \Omega_{\mathrm{T}}\right)
$$

we would have to solve:

[02]

$$
\left\langle 1+\mathrm{E}\left[\mathrm{r}\left(\mathrm{t}, \mathrm{T}, \Omega_{\mathrm{t}}\right)\right]\right\rangle .\left\langle 1+\mathrm{g}\left(\mathrm{t}, \mathrm{T}, \Omega_{\mathrm{t}} \rightarrow \Omega_{\mathrm{T}}\right)\right\rangle=\left\langle 1+\mathrm{r}\left(\mathrm{t}, \mathrm{T}, \Omega_{\mathrm{T}}\right)\right\rangle
$$

This gap rate is a good example of what is meant by a differential rate. However, there are other contexts where this type of rate comes in handy. 


\section{Remarks on notation:}

- The gap includes not only the starting and final valuation dates, but an explicit remark on the shift from one information set to the other.

- $\boldsymbol{\Omega}^{1}{ }_{\mathrm{t}} \rightarrow \boldsymbol{\Omega}{ }^{2} \mathrm{~T}$ means that the gap fills in what is not accounted for by $\boldsymbol{\Omega}^{1} \mathrm{t}$ at valuation date " $\mathrm{t}$ ", but it is accounted for by $\Omega^{2} \mathrm{~T}$, at valuation date " $\mathbf{T}$ ".

What [02] really conveys is that the gap of information between $\boldsymbol{\Omega}$ t and $\boldsymbol{\Omega}$ T can be quantified as a measure for the error made at assuming the rate forecast. This is a customary procedure for any budgetary task. The differential rate $\mathrm{g}\left(\mathrm{t}, \mathrm{T}, \Omega_{\mathrm{t}} \rightarrow \Omega \mathrm{T}\right)$ not only closes the gap between the ex ante and the ex post values, but provides with a performance measure as well.

But let us take now another perspective where, at the valuation date " $\mathrm{t}$ ", a specific cost item is assessed by means of the rate

$$
r\left(t, T, \Omega^{1}\right)
$$

and, at the same valuation date, we also have the assessment of a " global cost "item, inclusive of the former,

$$
r\left(t, T, \Omega^{2}\right)
$$

It follows that the specific cost has a smaller information set than the global cost, that is to say:

$$
\Omega^{1} \mathrm{t} \subseteq \Omega^{2} \mathrm{t}
$$

There will be a gap between both rates, which comes out of what is not accounted for the smaller information set. Such a gap can be measured by a differential rate

$$
g\left(t, T, \Omega^{1}{ }_{t} \Omega^{2}{ }_{t}\right)
$$

which is defined by

[03]

$$
\left\langle 1+r\left(t, T, \Omega^{1}{ }_{t}\right)\right\rangle .\langle 1+g(t, T)\rangle=\left\langle 1+r\left(t, T, \Omega^{2}\right)\right\rangle
$$

It is worthy of remark how different the contex of this example is from the former one. In [02] we have two valuation dates with their own specific information sets. In [03] we deal with only one valuation date and two specific information sets. In other words, the first example shows a "flow differential rate", and the second example highlights a "stock differential rate".

\section{Remark on notation:}

- $\Omega^{1}{ }_{t} \rightarrow \Omega{ }^{2}$ means that the gap fills in what is not accounted for by $\Omega^{1}$ t but it is accounted for by $\Omega^{2} \mathrm{t}$.

These examples have paved the way for a formal definition of differential rates. 
[04] Stock Differential Rate

$$
\left\langle 1+\mathrm{r}\left(\mathrm{t}, \mathrm{T}, \Omega^{\left.{ }^{1}{ }_{\mathrm{t}}\right)}\right\rangle .\left\langle 1+\mathrm{g}\left(\mathrm{t}, \mathrm{T}, \Omega^{{ }^{1}}{ }_{\mathrm{t}} \rightarrow \Omega^{{ }^{2}}{ }_{\mathrm{t}}\right)\right\rangle=\left\langle 1+\mathrm{r}\left(\mathrm{t}, \mathrm{T}, \Omega^{2}{ }_{\mathrm{t}}\right)\right\rangle\right.
$$

subject to the restriction $\quad \Omega^{1}{ }_{\mathrm{t}} \subseteq \Omega{ }^{2}{ }_{\mathrm{t}}$

[05] Flow Differential Rate

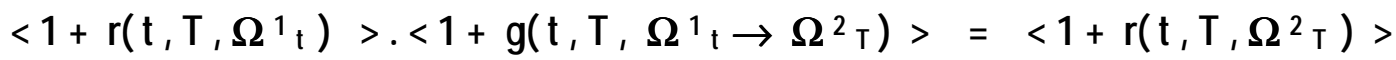

$$
\begin{aligned}
& \text { subject to the restriction } \quad \Omega^{1}{ }_{\mathrm{t}} \subseteq \Omega{ }^{2} \mathrm{~T}
\end{aligned}
$$

A more careful treatment of the information sets, grounded on algebras and rings of set will be founded in Apreda (2000). We want to keep this paper within a functional framework useful both to academics and practitioners, leaving tor the oncoming paper the mathematical details.

\section{NUMERICAL EXAMPLE: Stock differential rates}

Setting:

An investor wants to assess the impact of certain transaction costs in buying a financial asset.

Data:

Transaction costs amounts to $1,5 \%$ of the asset buying price. The security grants a nominal annual return of $9 \%$ for a holding period of six months.

Solution: By [04]

$$
\left\langle 1+r\left(t, T, \Omega^{1}{ }_{t}\right)>.\left\langle 1+g\left(t, T, \Omega^{1}{ }_{t} \rightarrow \Omega^{2}{ }_{t}\right)\right\rangle=\left\langle 1+r\left(t, T, \Omega^{2}{ }_{t}\right)\right\rangle\right.
$$

and we make:

$$
r\left(t, T, \Omega^{1}{ }_{t}\right)=0.0150 \quad r\left(t, T, \Omega^{2}{ }_{t}\right)=0.0450
$$

the differential rate yields:

$$
g\left(t, T, \Omega^{1}{ }_{t} \rightarrow \Omega^{2}{ }_{t}\right)=0.0296
$$




\section{Appraisal:}

What does $\mathrm{g}\left(\mathrm{t}, \mathrm{T}, \Omega^{{ }_{\mathrm{t}}} \rightarrow \Omega^{2} \mathrm{t}\right)$ mean?

Firstly, that the rate of return excluding the cost of transaction reaches only 2,96\% on the holding period. Secondly, it would be the maximum return the investor could claim unless there were other significant transaction costs to take into account.

\subsection{1.- THE REVERSE DIFFERENTIAL RATE}

Let us work with stock differential rates, as they are this paper main concern. In [04] was stated that

$$
\left\langle 1+\mathrm{r}\left(\mathrm{t}, \mathrm{T}, \Omega^{{ }^{1}}{ }_{\mathrm{t}}\right)>.\left\langle 1+\mathrm{g}\left(\mathrm{t}, \mathrm{T}, \Omega^{{ }^{1}}{ }_{\mathrm{t}} \rightarrow \Omega^{2}{ }_{\mathrm{t}}\right)\right\rangle=\left\langle 1+\mathrm{r}\left(\mathrm{t}, \mathrm{T}, \Omega^{2}{ }_{\mathrm{t}}\right)\right\rangle\right.
$$

What if we wanted to know how to explain $r\left(t, T, \Omega^{1} t\right)$ from the "global " rate $r\left(t, T, \Omega{ }^{2}\right)$ ? We would have to discount the latter to reach the former rate. This task is accomplished by the reverse differential rate.

and it leads to the equation

$$
\mathrm{b}\left(\mathrm{t}, \mathrm{T}, \Omega^{2}{ }_{\mathrm{t}} \rightarrow \Omega^{{ }^{1} \mathrm{t}}\right)
$$

[06]

$\left\langle 1+r\left(t, T, \Omega^{1}{ }_{t}\right)\right\rangle=\left\langle 1+r\left(t, T, \Omega^{2}{ }_{t}\right)\right\rangle,\left\langle 1+b\left(t, T, \Omega^{2}{ }_{t} \rightarrow \Omega^{1}{ }_{t}\right)\right\rangle$

There is a strong relationship between any differential rate and its reverse.

Lemma 1: Differential rates and their corresponding reverse rates fulfill the following relation

[07]

$$
<1+g\left(t, T, \Omega^{1}{ }_{t} \rightarrow \Omega^{2}{ }_{t}\right)>.<1+b\left(t, T, \Omega^{2}{ }_{t} \rightarrow \Omega^{1} t\right)>=1
$$

Proof: multiplying both sides in [04] by $<1+b\left(t, T, \Omega^{2}{ }_{t} \rightarrow \Omega^{1}{ }_{t}\right)>$

$$
\begin{gathered}
\left\langle 1+r\left(t, T, \Omega^{1}{ }_{t}\right)>.\left\langle 1+g\left(t, T, \Omega^{1}{ }_{t} \rightarrow \Omega^{2}{ }_{t}\right)>.\left\langle 1+b\left(t, T, \Omega^{2}{ }_{t} \rightarrow \Omega^{1}{ }_{t}\right)\right\rangle=\right.\right. \\
<1+r\left(t, T, \Omega^{2}{ }_{t}\right)>.\left\langle 1+b\left(t, T, \Omega^{2}{ }_{t} \rightarrow \Omega^{1}{ }_{t}\right)>\right.
\end{gathered}
$$

applying [06] to the right side and simplifying, it yields 


$$
\left\langle 1+g\left(t, T, \Omega^{1}{ }_{t} \rightarrow \Omega^{2}{ }_{t}\right)\right\rangle .\left\langle 1+b\left(t, T, \Omega^{2} t \rightarrow \Omega^{1}{ }_{t}\right)\right\rangle=1
$$

It is worth expanding on two consequences this lemma provides:

a) Relation [07] translates an equivalence between both gaps measures. In fact, $\mathbf{g}($, ) perform as it were an accrued rate of interest and $\mathbf{b}($,$) ) as it were a discount rate of interest, in the$ well known rate of interests arbitrage equation for interest rates in the money market:

$$
[1+i(t, T)] \cdot[1-d(t, T)]=1
$$

a) The difference with these financial mathematic relation lies in that any of both differential gaps, $\mathbf{g}($, ) and $\mathbf{b}($, ), can adopt negative signs, remaining positive the other one. Instead, the discount rate is the only to be preceded by the negative sign in the equivalence showed in point a).

b) Lemma 1 allows to net a gross rate or, symmetrically, to gross up a net rate, by means of differential rate, as we will see in Lemma 3.

\section{NUMERICAL EXAMPLE: Reverse differential rates}

\section{Setting:}

Going on with the example of section 03 , on page 8, we can ask for the rate of discount the nominal rate of return will suffer to produce the $2,96 \%$ at last.

Solution:

By [07]

$\left\langle 1+r\left(t, T, \Omega^{1}{ }_{t}\right)\right\rangle=\left\langle 1+r\left(t, T, \Omega^{2}{ }_{t}\right)\right\rangle .\left\langle 1+b\left(t, T, \Omega^{2}{ }_{t} \rightarrow \Omega^{1}{ }_{t}\right)\right\rangle$

that is to say:

$$
1,0296=1,045 .<1+b\left(t, T, \Omega^{2}{ }_{t} \rightarrow \Omega^{1}{ }_{t}\right)>
$$

and hence

$$
\mathrm{b}\left(\mathrm{t}, \mathrm{T}, \Omega^{2}{ }_{\mathrm{t}} \rightarrow \Omega^{{ }^{1}}\right)=0.0147
$$

\subsection{2- TRANSACTION COSTS AS DIFFERENTIAL RATES}

Suppose that $\mathbf{V C}(t)$ measures the nominal variable cost of an underlying variable $\mathbf{X}(\mathrm{t})$ ). The latter could mean, for our purposes, the price of a commodity or a financial. Also the volume bought of a financial in a single transaction. 
Then, we can solve for $\mathbf{v c}(\mathrm{t})$, the rate of variable cost involved in this transaction:

[08]

$$
v c(t)=v c(t) \cdot x(t)
$$

This is the usual concept of variable cost rate, that comes as a percentage of the nominal value of a stock variable $\mathbf{X}(\mathrm{t})$. Sometimes it is said that these sort of costs comes from volume or quantity.

Instead, suppose now that $\mathrm{FC}(\mathrm{t})$ is the nominal value of fixed costs the economic agent faces whenever he deals with financial transactions. Is there a way to measure fixed costs by means of a rate $\mathrm{fc}(\mathrm{t})$ ? In fact, we can solve:

[09]

$$
F C(t)=f c(t) \cdot X(t)
$$

In the practice of real markets, however, there are step-wise functions to express fixed costs, as it takes place with postage weights. In reality, these are semi-fixed costs, and they could be translated this way:

[10]

$$
F C(t) \begin{cases}F C^{1}(t) & \text { if } a_{1} \leq X(t)<a_{2} \\ F C^{2}(t) & \text { if } a_{2} \leq X(t)<a_{3} \\ F C^{3}(t) & \text { if } a_{3} \leq X(t)<a_{4} \\ \cdot & \\ - & \\ F C^{N}(t) & \text { if } a_{N-1} \leq X(t)<a_{N}\end{cases}
$$

In this case, we solve for the fixed cost rate attibutable to each of the pieces the funtion is made.

Let us assume we are working with certain global rate $\mathbf{r}\left(\mathrm{t}, \mathrm{T}, \boldsymbol{\Omega}{ }^{{ }_{\mathrm{t}}}\right)$ and we can assess, by using [08], the rate of variable costs, $\mathbf{v c}\left(\mathbf{t}, \mathbf{T}, \boldsymbol{\Omega} \mathrm{vc}_{\mathrm{t}}\right)$, that affect the former rate conditional to its information set $\Omega \mathrm{vc}_{\mathrm{t}}$. Then, by [04] we have

[11]

$$
\left\langle 1+v c\left(t, T, \Omega^{v_{t}}\right)>.\left\langle 1+g\left(t, T, \Omega^{1}{ }_{t} \rightarrow \Omega^{2}{ }_{t}\right)\right\rangle=\left\langle 1+r\left(t, T, \Omega^{2}{ }_{t}\right)\right\rangle\right.
$$

where $\mathbf{g}($,$) can be assimilated to a net rate, exclusive of the variable cost rate.$ 
Furthermore, drawing from [09] and [10], we proceed to the rate of fixed costs assessment, $\mathbf{f c}(\mathbf{t}$, $\mathrm{T}, \boldsymbol{\Omega} \mathrm{fc}_{\mathrm{t}}$ ), which affect the global rate and it is conditional to its own information set. Moreover, if this assessment were introduced in [11], it would yield

[12]

$$
\begin{aligned}
& \left\langle 1+\mathrm{vc}\left(\mathrm{t}, \mathrm{T}, \Omega^{\mathrm{vc}} \mathrm{t}_{\mathrm{t}}\right)\right\rangle .\left\langle 1+\mathrm{fc}\left(\mathrm{t}, \mathrm{T}, \Omega^{\left.\mathrm{fc}_{\mathrm{t}}\right)}\right\rangle .\left\langle 1+\mathrm{g}\left(\mathrm{t}, \mathrm{T}, \Omega_{\mathrm{vc}} \cup \Omega^{\mathrm{fc}} \mathrm{t}_{\mathrm{t}} \rightarrow \Omega^{2}{ }_{\mathrm{t}}\right)\right\rangle=\right. \\
& <1+\mathrm{r}\left(\mathrm{t}, \mathrm{T}, \Omega^{2} \mathrm{t}\right)>
\end{aligned}
$$

Now $\mathbf{g}($,$) adds up to a net rate which excludes both the variable and the fixed cost rates.$ Moreover, it performs as the net rate of $\mathrm{r}\left(\mathrm{t}, \mathrm{T}, \Omega^{2} \mathrm{t}\right)$. Mathematical foundation by using algebras and rings of sets can be found in Apreda (2000).

Summing up: variable and fixed cost rates are differential rates.

\section{NUMERICAL EXAMPLE : Variable and fixed costs as differential rates}

Data:

A fund manager faces a variable cost for each buying transaction of $0.80 \%$ over price per unit of asset. Fixed costs on this type of trading amounts to 2 dolllars per unit. Quotation asked price is, at valuation date " $t$ ", equal to 62 dollars. Besides, regardless of volume and type of asset, he runs a fixed cost charge, on regulatory groundings, of 2,50 dollars for each transaction.

Solution:

$$
v c(t)=0.0080
$$

From [09] he must figure out $\mathrm{fc}(\mathrm{t})$

$$
4,50=62 \cdot \mathrm{fc}(\mathrm{t}) \quad \Rightarrow \quad \mathrm{fc}(\mathrm{t})=0.0726
$$

Furthermore, he has assessed that the nominal rate of return could reach $14 \%$ annual, along a holding period of six months. What would be the impact of transaction costs on this rate?

By [12]

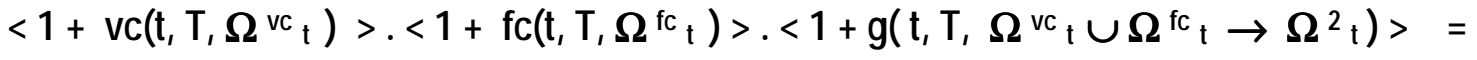

$$
\begin{aligned}
& \left\langle 1+\mathrm{r}\left(\mathrm{t}, \mathrm{T}, \Omega^{2}{ }_{\mathrm{t}}\right)\right\rangle
\end{aligned}
$$

when replacing we get:

$$
1.0080 \cdot 1.0726 \cdot\left\langle 1+g\left(t, T, \Omega^{v c}{ }_{t} \cup \Omega^{f_{t}} \rightarrow \Omega^{2}{ }_{t}\right)>=1.0700\right.
$$

and solving for $g\left(t, T, \Omega^{1}{ }_{t} \rightarrow \Omega{ }^{2}\right)$ 


$$
g\left(t, T, \Omega^{v c_{t}} \cup \Omega^{{ }^{\mathrm{fc}}}{ }_{\mathrm{t}} \rightarrow \Omega{ }^{\mathrm{t}}\right)=-0.0103
$$

\section{Appraisal:}

We can bring out some conclusions about this simple illustration:

a) What would the "global" rate of transaction costs amount to? We should have to solve

$$
1.0080 \cdot 1.0726=\left\langle 1+\mathrm{tc}\left(\mathrm{t}, \mathrm{T}, \Omega_{\left.\mathrm{tc}_{\mathrm{t}}\right)}\right)\right\rangle
$$

that yields

$$
\mathrm{tc}\left(\mathrm{t}, \mathrm{T}, \Omega_{\mathrm{tc}}^{\mathrm{tc}}\right)=0.0812
$$

b) That asset seems not worthy of being included in the manager's portfolio, because it doesn't cover transaction costs.

\subsection{3.- THE TRANSACTION COSTS FUNCTION IN A MULTIPLICATIVE MODEL OF DIFFERENTIAL RATES}

By the analysis performed in last section involving variable and fixed rates, and profitting from [11] and [12], we can handle transaction costs as differential rates.

[13] The Transaction Costs Function

$$
\begin{aligned}
& \left\langle 1+\operatorname{TC}\left(t, T, \Omega^{T^{T}}{ }_{t}\right)\right\rangle=\left\langle 1+\operatorname{INT}\left(t, T, \Omega^{{ }^{N T}} t\right)\right\rangle .\left\langle 1+\operatorname{MICR}\left(t, T, \Omega^{M I C R}{ }_{t}\right)\right\rangle \\
& .<1+\operatorname{TAX}\left(t, T, \Omega^{\operatorname{TAX}_{t}}\right)>.<1+\operatorname{INF}\left(t, T, \Omega^{\operatorname{NNF}_{t}}\right)>.\left\langle 1+\operatorname{FIN}\left(t, T, \Omega \operatorname{FIN}_{t}\right)\right\rangle
\end{aligned}
$$

with the restriction that

$$
\boldsymbol{\Omega}^{k_{\mathrm{t}}} \subseteq \boldsymbol{\Omega}^{\mathrm{TC}_{\mathrm{t}}} \text { for } \mathrm{k}: \text { INT, MICR, INF, FIN, TAX }
$$

It can be seen that [13] is underpinned by a multiplicative model from which the extension to a continuous model is straightforward, and can be found in Apreda (1999-b).

Remarks on notation:

- TC, INT, MICR, FIN, TAX, INF must be read as the corresponding cost rates. 
- We left out $m_{1}$ and $m_{2}$ for ease of notation. In a context where two markets come up, they should be necessary, by all means, as is the case with foreign currency markets.

\section{NUMERICAL EXAMPLE : The transaction costs function stems from differential rates}

Setting:

An investment fund manager would be ready to make an important buying order abroad to change his portfolio risk-return profile.

Data:

The analysis of the transaction costs function shows the following features:
a) Intermediation costs:
$1.10 \%$
b) Taxes:
$0.80 \%$

c) Information costs:

$0.90 \%$ (mainly tax, legal and trading advisory for both markets)

d) Microstructure:

$1.20 \%$ (regulations in both capital markets and foreign exchange trading procedures)

e) Financial costs

$1.40 \%$ (mainly for marginal account fees to mark to market the future contract, collaterals and a loan to complete the whole amount to invest)

Solution:

By [13]

$$
\begin{aligned}
& \left\langle 1+\operatorname{TC}\left(t, T, \Omega^{T^{T}}\right)\right\rangle=\left\langle 1+\operatorname{INT}\left(t, T, \Omega^{\operatorname{INT}_{t}}\right)\right\rangle .\left\langle 1+\operatorname{MICR}\left(t, T, \Omega^{\operatorname{MICR}_{t}}\right)\right\rangle \\
& .\left\langle 1+\operatorname{TAX}\left(t, T, \Omega^{\operatorname{TAX}_{t}}\right)\right\rangle .\left\langle 1+\operatorname{INF}\left(t, T, \Omega^{\operatorname{INF}_{t}}\right)\right\rangle .\left\langle 1+\operatorname{FIN}\left(t, T, \Omega^{\operatorname{FIN}_{t}}\right)\right\rangle
\end{aligned}
$$

and replacing with data:

$$
\begin{gathered}
\left\langle 1+\mathrm{TC}\left(\mathrm{t}, \mathrm{T}, \Omega_{\mathrm{TC}}\right)\right\rangle=1.0110 \cdot 1.0080 \cdot 1.0090 \cdot 1.0120 \cdot 1.0140 \\
\left.<1+\mathrm{TC}\left(\mathrm{t}, \mathrm{T}, \Omega^{\mathrm{TC}}{ }_{\mathrm{t}}\right)\right\rangle=1.0552
\end{gathered}
$$

hence

$$
\mathrm{TC}\left(\mathrm{t}, \mathrm{T}, \Omega_{\mathrm{TC}}\right)=0.0552
$$




\section{Appraisal:}

The investment manager faces an upfront cost of $5,52 \%$ to be matched against the nominal return of the planned investment. Thus, he should think it over again his decision,because other alternatives with fewer transaction costs could become more suitable for him.

\section{4.- $\quad$ COMPUTING NET RATES OF RETURN FROM OF FINANCIAL ASSETS}

As from now, our holding period will be [ $\mathrm{t} ; \mathrm{T}$ ]. The nominal total rate of return of buying, shortselling, holding and selling a financial asset along this period comes from the following relationship:

[14]

$$
r(t, T)=[P(T)+I(t, T)-P(t)] / P(t)
$$

Remark on notation:

$r(t, T)$ : total nominal return provided by a financial asset in the holding period.

$P(T)$ : nominal selling price of the asset at valuation date " $T$ ".

$P(t)$ : nominal buying price of the asset at valuation date " $t$ ".

I( $t, T)$ : any income collected from the asset during the holding period (for instance, dividends or coupon interests).

It is worth pointing out that, from the point of view of the analyst who tries to compute ex ante and ex post total holding returns from financial assets, $\mathbf{P}(\mathrm{t})$ can be either the actual buying price (the bid price quoted and settled by the dealer), or some sensible valuation model assessment, in all cases as if the analyst were about to buy the asset. By the same token, $\mathbf{P}(\mathbf{T})$ can be either the actual selling price at valuation date " $\mathrm{T}$ " (the asked price quoted and settled by the dealer), or by means of a future contract at valuation date " $t$ ", or an ex ante valuation model assessment, in all cases as if the analyst were about to sell the asset.

It is usual that institutional investors or banks, by regulations in their markets, must provide periodical information of many things, including returns in portfolios or single assets. In this case, the analyst follows a market value criterion and supposes he is about to sell the asset, in order to have the holding period return, although no selling will take place eventually.

Now, we move ahead to prove two useful lemmas. The first tells us that the nominal return has two distinctive sources: a holding return and an income return. This very simple statement comes in handy to institutional investors and accountants. The second lemma is a powerful, although simple, statement, since it shows how to deal with net of transaction costs rates of return.

\section{Lemma 2: $r(t, T)$ can be broken down into holding returns and income returns.}

Proof: let us call holding return, $H R(t, T)$, to 


$$
H R(t, T)=[P(T)-P(t)] / P(t)
$$

and income return, $I R(t, T)$, to

then,

$$
I R(t, T)=I(t T) / P(t)
$$

[15]

$$
r(t, T)=H R(t, T)+I R(t, T)
$$

If we introduce transaction costs related to [14] we will have to bear in mind their actual sources:

a) $c(t)$, when buying the security, at valuation date " $t$ ".

b) $\mathbf{c}(\mathbf{T})$, when selling the security, at valuation date " $\mathbf{~}$ ".

c) $c(t, T)$, that accounts for all transactions costs incurred with the collection of any income cash flow composing $\mathrm{I}(\mathrm{t}, \mathrm{T})$.

Therefore, we have to compute the net rate of return, during the holding period, with a cash-flow perspective:

a) Adding to the acquisition value $P(t)$ the cost of the transaction, that gives $P(t) . c(t)$, we get:

$$
P(t) \cdot[1+c(t)]
$$

That is to say, the investment we make is not given by the purchase value $P(t)$ only, as is usually told in text-books, but by the expression above, because both items are outgoing cashflows .

b) By the same token, we substract from the selling value $P(T)$ the cost of the transaction, that gives $P(T) \cdot c(T)$

$$
P(T) \cdot[1-c(T)]
$$

Here we have an incoming cash flow and an outgoing one, and the balance provide with a net cash flow.

c) Although the income component of [14] is treated as in point b),

$$
\mathrm{l}(\mathrm{t}, \mathrm{T}) \cdot[1-\mathrm{c}(\mathrm{t}, \mathrm{T})]
$$

we must give a further qualification. Perhaps the holding period is long enough to provide with more than one cash flow. In this case, each of them must be associated with their transaction costs, and the final expression would require a comprehensive transaction costs rate. 
For example, suppose that two cash flows ( carrying on dividends or coupons, for instance ), CF $\left(t_{1}\right)$ and $\mathbf{C F}\left(t_{2}\right)$, are collected along $[t ; T$ ]. Then, taking transaction costs into account would yield:

$$
C F\left(t_{1}\right) \cdot\left[1-c\left(t_{1}\right)\right]+C F\left(t_{2}\right) \cdot\left[1-c\left(t_{2}\right)\right]
$$

This can also be translated as:

$$
C F\left(t_{1}\right) \cdot\left[1-c\left(t_{1}\right)\right]+C F\left(t_{2}\right) \cdot\left[1-c\left(t_{2}\right)\right]=\left[C F\left(t_{1}\right)+C F\left(t_{1}\right)\right] \cdot[1-c(t, T)]
$$

Summing up: from this cash flow perspective, we reach then at:

[16]

$$
\begin{gathered}
1+\operatorname{net} r(t, T)= \\
\{P(T) \cdot[1-c(T)]\} /\{P(t) \cdot[1+c(t)]\}+\{I(t, T) \cdot[1-c(t, T)]\} /\{P(t) \cdot[1+c(t)]\}
\end{gathered}
$$

Now, we can make the following definition for a rate of return to become net of transaction costs.

[17] Net Rate of Return

net $r(t, T)=$

$$
\{P(T) \cdot[1-c(T)]+I(t, T) \cdot[1-c(t, T)]-P(t) \cdot[1+c(t)]\} /\{P(t) \cdot[1+c(t)]\}
$$

Remark on cash flow reinvestments:

When a set of cash flows take place alont the period $[\mathrm{t} ; \mathrm{T}$ ], it is sensible to allow for their reinvestment. Let us illustrate the case of the two cash flows we used in point c) above, with reinvestments to take place in short term money market securities, at dates " $\mathrm{t}_{1}$ " and " $\mathrm{t}_{2}$ ", respectively:

$$
\begin{gathered}
C F\left(t_{1}\right) \cdot\left[1-c\left(t_{1}\right)\right] \cdot\left[1+i\left(t_{1}, T\right) \cdot\left(1-c\left(t_{1}, T\right)\right)\right] \\
+C F\left(t_{2}\right) \cdot\left[1-c\left(t_{2}\right)\right] \cdot\left[1+i\left(t_{2}, T\right) \cdot\left(1-c\left(t_{2}, T\right)\right)\right] \\
\left.\left\{C F\left(t_{1}\right) \cdot\left[1+i\left(t_{1}, T\right)\right]+C F\left(t_{2}\right)\right] \cdot\left[1+i\left(t_{2}, T\right)\right]\right\} \cdot[1-c(t, T)]
\end{gathered}
$$

Lemma 3: The total return of a financial asset over the holding period [ $t ; T$ ] can be expressed as a rate of return net of transaction costs. Besides, the total return can be broken down into a net return and a differential rate that accounts for transaction costs.

Proof: We know, by [16], that 


$$
1+\operatorname{net} r(t, T)=
$$

$\{P(T) \cdot[1-c(T)]\} /\{P(t) \cdot[1+c(t)]\}+\{I(t, T) \cdot[1-c(t, T)]\} /\{P(t) \cdot[1+c(t)]\}$

But the right hand can be translated in a convenient way as:

[18]

$\{P(T) \cdot[1-c(T)]\} /\{P(t) \cdot[1+c(t)]\}+\{I(t, T) \cdot[1-c(t, T)]\} /\{P(t) \cdot[1+c(t)]\}=$ $[1 /(1+c(t))] \cdot[\{P(T)+I(t, T)\} /\{P(t)\}-\{P(T) \cdot c(T)+I(t, T) \cdot c(t, T)\} /\{P(t)\}]=$ $[1 /(1+c(t))] \cdot[\{1+r(t, T)\}-\{P(T) \cdot c(T)+I(t, T) \cdot c(t, T)\} /\{P(t)\}]$

Furthermore, it holds true that

[19]

$$
\{P(T) \cdot c(T)+I(t, T) \cdot c(t, T)\} /\{P(t)\}=
$$

$\alpha \cdot[\{P(T)+I(t, T)\} /\{P(t)\}] \cdot c(T)+(1-\alpha) \cdot[\{P(T)+I(t, T)\} /\{P(t)\}] \cdot c(t, T)$

whenever we take:

$$
\alpha=P(T) /[P(T)+I(t, T)]
$$

Now, we can see that [18] is equivalent to:

[20]

$$
\begin{gathered}
P(T) \cdot c(T)+I(t, T) \cdot c(t, T)\} /\{P(t)\}= \\
\alpha \cdot[1+r(t, 1 T)] \cdot c(T)+(1-\alpha) \cdot[1+r(t, T)] \cdot c(t, T)
\end{gathered}
$$

Therefore, replacing [20] in [18]

$\{P(T) \cdot[1-c(T)]\} /\{P(t) \cdot[1+c(t)]\}+\{I(t, T) \cdot[1-c(t, T)]\} /\{P(t) \cdot[1+c(t)]\}=$ $[1 /(1+c(t))] \cdot[\{1+r(t, T)\}-\alpha \cdot\{1+r(t, T)\} \cdot c(T)-(1-\alpha) \cdot\{1+r(t, T)\} \cdot c(t, T)]=$ $\{1+r(t, T)\} \cdot[1-\alpha \cdot c(T)-(1-\alpha) \cdot c(t)] \cdot[1 /(1+c(t))]$

Hence,

$$
\begin{gathered}
1+\operatorname{net} r(t, T)= \\
\{1+r(t, T)\} \cdot[1-\alpha \cdot c(T)-(1-\alpha) \cdot c(t, T)] \cdot[1 /(1+c(t))]
\end{gathered}
$$


and taking

[21]

$$
(1+b(t, T))=[1-\alpha \cdot c(T)-(1-\alpha) \cdot c(t, T)] \cdot[1 /(1+c(t))]
$$

we get:

[22]

$$
1+\operatorname{net} r(t, T)=[1+r(t, T)] \cdot[1+b(t, T)]
$$

By Lemma 1,

$$
[1+g(t, T)] \cdot[1+b(t, T)]=1
$$

and [16] can be rewritten in this form:

[23]

$$
1+r(t, T)=[1+\operatorname{net} r(t, T)] \cdot[1+g(t, T)]
$$

NUMERICAL EXAMPLE : The net rate of return of a financial asset

Setting:

An investor wants to buy, hold for six months, and then sell certain financial asset. Here are his data:

Data:

- Transaction Costs:

$$
c(t)=1 \% \quad c(t, T)=0.5 \% \quad c(T)=0.8 \%
$$

- Expected Cash Flows:

$$
P(t)=76 \quad E\left[P\left(T, \Omega_{t}\right)\right]=82 \quad E\left[I\left(t, T, \Omega_{t}\right)\right]=5
$$

Solution:

He makes for to compute the rates of return.

a) Nominal rate of return: by using [14]

$$
\begin{gathered}
r(t, T)=[P(T)+I(t, T)-P(t)] / P(t) \\
r(t, T)=[82+5-76] / 76=0,1447
\end{gathered}
$$

b) Then, he applies [16] to find out the net rate of return 


$$
\begin{gathered}
1+\text { net } r(t, T)= \\
\{P(T) \cdot[1-c(T)]\} /\{P(t) \cdot[1+c(t)]\}+\{I(t, T) \cdot[1-c(t, T)]\} /\{P(t) \cdot[1+c(t)]\}
\end{gathered}
$$

and replacing by the data:

$$
\begin{gathered}
1+\text { net } r(t, T)=[82 .(1-0.008)-5 \cdot(1-0.0005)-76 \cdot(1+0.01)] / 76.1 .01 \\
1+\text { net } r(t, T)=1.1245
\end{gathered}
$$

The net rate of returns is equal to $12,45 \%$.

c) At last, he needs to measure the "global " influence of transaction costs, by using [23]

$$
1+r(t, T)=[1+\operatorname{net} r(t, T)] \cdot[1+g(t, T)]
$$

replacing and solving, we get:

$$
1.1447=1.1245 \cdot[1+g(t, T)] \quad \Rightarrow \quad g(t, T)=0.0180
$$

d) Alternatively, he could have used Lemma 3, by taking firstly [19]

$$
\alpha=P(T) /[P(T)+I(t, T)]=0.9425
$$

then [21]

$$
\begin{gathered}
(1+b(t, T))=[1-\alpha \cdot c(T)-(1-\alpha) \cdot c(t, T)] \cdot[1 /(1+c(t))] \\
\Rightarrow \quad b(t, T)=-0.0177
\end{gathered}
$$

and lastly, resort to Lemma 1 so as to obtain $\mathbf{g}(\mathrm{t}, \mathrm{T})=\mathbf{0 . 0 1 8 0}$.

\section{5.- CONCLUSIONS}

Any buying, short-selling, holding and selling of a financial comes round with a cluster of transaction costs which are not limited to trading costs only. In fact, the transaction costs function involves five broad categories: intermediation, tax, information, microstructure and financial costs.

To account for this complexitiy, differential rates prove to be a useful device because they allow us to make explicit the transaction costs function, and to break down the return of any financial asset in a differential rate that stands for a return net of transaction costs and another differential rate that stands for transaction costs only.

The approach might be suitable not only for financial economists and practitioners, but also to accountants and auditors. 


\section{6.- REFERENCES}

Apreda, Rodolfo. 1993

Arbitraje en divisas

Revista del Instituto Argentino de Ejecutivos de Finanzas, Abril, pp. 29-33.

Apreda, Rodolfo. 1995

Ingeniería Financiera 1

Cuadernos UADE, № 38 , Buenos Aires.

Apreda, Rodolfo. 1998-a

Financial Costs, Dynamic Gaps and Arbitrage

Ph.D. Dissertation, University of Buenos Aires, Buenos Aires.

Apreda, Rodolfo. 1998-b

Complex Financial Dynamics for Arbitrage Gaps

Paper presented at the 34 Annual Meeting, Eastern Finance Association, April, Williamsburg, Virginia.

Apreda, Rodolfo. 1998-c

Dynamic Arbitrage Gaps for Financial Assets

The University of Cema, Working Papers, August, № 134, Buenos Aires.

Apreda, Rodolfo. 1999-a

Transactionally Efficient Markets, Dynamic Arbitrage and Microstructure

Paper presented at the 35 Annual Meeting, Eastern Finance Association, Miami, Florida, April.

and published in The University of Cema, Working Papers, July, $N^{\circ} 151$, Buenos Aires.

Apreda, Rodolfo. 1999-b.

Dynamic Arbitrage Gaps for Financial Assets in a Non-linear and Chaotic Price Adjustment Process.

Journal of Multinational Financial management, vol. 9, pp. 441-457, Elsevier Holland.

Apreda, Rodolfo. 2000

Differential Rates and Information Sets

The University of Cema, Working Papers, forthcoming in July.

Arnott, Robert. 1998

Trading Costs

In Investment Management (Eds. P.Bernstein and A. Damodaran), John Wiley, New York.

Benston, George and Clifford Smith. 1976

A Transactions Cost Approach to the Theory of Financial Intermediation

Journal of Finance, Vol 31, May, pp. 215-231.

Blake, David. 1999

Financial Market Analysis

Second Edition, John Wiley, London.

Carr, Nicholas. 2000

Hypermediation

Harvard Business Review, January-February, pp. 46-47

Damodaran, Aswath. 1998

The Hidden Costs of Trading

In Investment Management (Eds. P.Bernstein and A. Damodaran), John Wiley, New York. 
Day, Richard. 1994

Complex Economic Dynamics

Volume 1, The Mit Press, Massachusetts.

Flood, Mark et al. 1998

Search Costs: The Neglected Spread Component

Institute of Business and Economic Research, RPF-285, University of California, Berkeley.

Frankel, Jacob and Levich, Richard. 1973

Covered Interest Arbitrage: Unexploited Profits?

Journal of Political Economy, vol. 83, n² 2, pp. 325-338.

Grossman, Herschell. 1974

The Nature of Quantities in Market Disequilibrium

The American Economic Review, vol. 64, n³, pp. 509-517.

Hart, Oliver. 1997

Firms Contracts and Financial Structure

Clarendon Lectures in Economics, Clarendon Press, Cambridge.

Jeffrey, Robert. 1998

Tax Considerations in Investing

In Investment Management (Eds. P.Bernstein and A. Damodaran), John Wiley, New York.

Jeffrey, Robert. 1998

Taxes and Performance Evaluation

In Investment Management (Eds. P.Bernstein and A. Damodaran), John Wiley, New York.

Levy, A. and Livingston, M. 1995

The Gains from Diversification Reconsidered: Transaction Costs and Superior Information

Financial Markets, Institutions and Instruments, New York University, Solomon Center, vol. 4, n³, pp. 1-57.

Marshall, J. and Kapner, K. 1993

Understanding Swaps

John Wiley, New York.

Mayshar, Joram. 1981

Transaction Costs and the Pricing of Assets

The Journal of Finance, Vol 36, №3, June, pp. 583-597.

Neal, Robert. 1992

A Comparison of Transaction Costs between Competitive Market Maker and Specialist Market Structure

Journal of Business, vol 65, N03, pp. 317- 334.

Okun, Arthur. 1981

Prices and Quantities

The Brookings Institution, Washington.

Spulber, Daniel. 1996

Market Microstructure and Intermediaries

Journal of Economic Perspectives, vol. 10, pp. 135-152.

Spulber, Daniel. 1999

Market Microstructure: Intermediaries and the Theory of the Firm

Cambridge University Press, Cambridge. 
Treynor, Jack. 1994

The Invisible Costs of Trading

The Journal of Portfolio Management, Fall, pp. 71-78.

Williamson, Oliver. 1996

Transaction-Cost Economics: the Governance of Contractual Relations

In Firms, Organizations and Contracts ( A Reader in Industrial Organization )

Edited by Peter Buckley and Jonathan Michie, Oxford University Press, Oxford

Williamson, Oliver. 1996

The Mechanisms of Governance

Oxford University Press, Oxford. 